\title{
Máquina com água como combustível: alerta para erros de informação
}

\author{
VICTOR M. M. L O B O
}

Um "relógio a água" comercializado [1] em Portugal indica no folheto que 0 acompanha "Não precisa de pilha para funcionar. O único "combustivel" de que precisa é a água, ou praticamente qualquer outro fluido electrolítico."

É meu objectivo pedir aos professores de física e química de todos os graus de ensino que alertem os seus alunos para os erros científicos relacionados com o acima exposto. Infelizmente, é com alguma frequência que aparecem notícias na comunicação social sobre pessoas que teriam "inventado" motores utilizando água como combustível, e na minha já longa vida tenho inúmeras vezes conversado com pessoas (e até de certo nivel de instrução) que acreditam nessa possibilidade, por vezes dizendo que são as companhias petrolíferas que tal impedem! É pois importante educarmos os nossos alunos para esta problemática.

Talvez seja bom esclarecer os alunos para perceberem o que significa aquilo que talvez ouçam dos seus avós: no

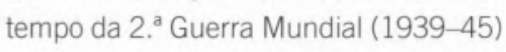
utilizou-se em Portugal (e noutros países) um sistema de propulsão dos automóveis baseados na passagem de vapor de água sobre carvão mineral em brasa, daí resultando uma mistura gasosa que subsequentemente alimentava os cilindros, explodia (tal como a gasolina) e efectivamente fazia andar o automóvel (embora com uma eficiência muito menor do que no caso da gasolina). Para tal, atrelava-se ao automóvel um reboque (o "gasogénio") que continha uma caldeira geradora de vapor de água que logo passava pelo carvão a arder. Tal causava a dissociação térmica da água, digamos,

$2 \mathrm{H}_{2} \mathrm{O}(\mathrm{g})+$ Energia $\rightarrow 2 \mathrm{H}_{2}(\mathrm{~g})+\mathrm{O}_{2}(\mathrm{~g})$

e esta mistura de hidrogénio e oxigénio (tendo também produtos resultantes da oxidação incompleta do carvão, formando tudo o "gás pobre") explodia nos cilindros segundo, claro,

$2 \mathrm{H}_{2}(\mathrm{~g})+\mathrm{O}_{2}(\mathrm{~g}) \rightarrow 2 \mathrm{H}_{2} \mathrm{O}(\mathrm{g})+$ Energia

Dizem alguns: aí está um motor a água! Claro que a água é o "veículo" que transporta a energia resultante da combustão do carvão, digamos

$\mathrm{C}(\mathrm{s})+\mathrm{O}_{2}(\mathrm{~g}) \rightarrow \mathrm{CO}_{2}(\mathrm{~g})+$ Energia

para dentro dos cilindros, onde depois tal energia é convertida em energia mecânica. Mas também o é na clássica máquina a vapor que provocou a Revolução Industrial. Contudo, a água não é o combustivel: o carvão é que o é.

Também é verdade que podemos obter muita energia da fusão do hidrogénio (deutério) tal como na "bomba de hidrogénio". Esse hidrogénio pode ser retira- do da água por electrólise. Contudo, também não seria apropriado, em terminologia corrente, dizer-se que, por isso, a água é um combustível. (De qualquer modo, ponho largas dúvidas que seja por fusão nuclear que se obtenha a energia para o relógio! Teríamos a tal "fusão a frio"!). Outros exemplos se poderiam dar, como o das barragens hidroeléctricas, etc.

O conceito comum de combustivel refere-se a uma dada substância que se pode transformar noutras, sem significativas alterações de pressão e temperatura (entre o estádio inicial e o final), segundo uma reacção química que, no balanço global, liberte energia. (Dito de outro modo, e considerando T, P = Ctes, um reacção onde a variação de energia (livre) de Gibbs seja negativa [2]). É o que acontece quando se queima metano, $\mathrm{CH}_{4}$, o principal constituinte do gás natural,

$\mathrm{CH}_{4}(\mathrm{~g})+2 \mathrm{O}_{2}(\mathrm{~g}) \rightarrow \mathrm{CO}_{2}(\mathrm{~g})+2 \mathrm{H}_{2} \mathrm{O}(\mathrm{g})+$ Energia

iso-octano (constituinte da gasolina)

$2 \mathrm{C}_{8} \mathrm{H}_{18}(\mathrm{~g})+24 \mathrm{O}_{2}(\mathrm{~g}) \rightarrow 16 \mathrm{CO}_{2}(\mathrm{~g})+18 \mathrm{H}_{2} \mathrm{O}$ + Energia

álcool etílico (já utilizado no Brasil para substituir a gasolina) 
$\mathrm{CH}_{3} \mathrm{CH}_{2} \mathrm{OH}(\mathrm{I})+3 \mathrm{O}_{2}(\mathrm{~g}) \rightarrow 2 \mathrm{CO}_{2}(\mathrm{~g})+$ $3 \mathrm{H}_{2} \mathrm{O}(\mathrm{g})+$ Energia

e muitos outros casos.

Note-se que nos tão falados autocarros a hidrogénio (e.g., na cidade do Porto) não temos aí uma reacção de combustầo do hidrogénio, mas sim uma reacçāo electroquímica. É a reacção inversa da da electrólise da água. Nesta fornece-se energia eléctrica e obtém-se $\mathrm{O}_{2}$ e $\mathrm{H}_{2}$; na primeira fornece-se $\mathrm{H}_{2}$ e $\mathrm{O}_{2}$ e obtém-se energia eléctrica. É a chamada pilha de combustivel, que foi extensamente utilizada nas missões Apolo, que há 30 anos foram à Lua.

Ora, não é possivel haver uma reacção química que, similarmente ao $\mathrm{CH}_{4}$, $\mathrm{C}_{8} \mathrm{H}_{18} \ldots$, transforme a $\mathrm{H}_{2} \mathrm{O}$ noutras substâncias num processo que liberte energia. Por outras palavras, a $\mathrm{H}_{2} \mathrm{O}$ estará num estado energético mais baixo possivel. Assim a água nunca pode ser um combustivel.

Voltemos a citar frases do texto do folheto que acompanha o tal relógio de água:

"Os conceitos de sobrevoltagem e de transferência de carga em interfaces foram aplicados, e construiu-se um conversor de energia; os electrōes são extraídos das moléculas de água, formando um fluxo contínuo de corrente eléctrica que faz funcionar o relógio."

"Construiu-se um conversor de energia em que a água e outros fluidos electroliticos podem ser usados como 'combustiveis' para gerar electricidade para fazer funcionar o relógio."

Escusado será dizer que qualquer químico ou físico fica perturbado com estas afirmações.

Contactei a firma e consegui mesmo falar com a sua responsável, sendo ela e todos os seus funcionários muito atenciosos e totalmente disponiveis para resolver qualquer problema de mau funcionamento do produto. Contudo, e compreensivelmente, não estavam em condiçōes de analisar o conteúdo científico do folheto informativo, nem de dar posteriores informaçōes sobre o funcionamento do relógio. Não pretendo fazer qualquer crítica à firma; pelo contrário, talvez os ajude a solicitar aos seus fornecedores mais cuidado na escrita dos folhetos informativos, já que me parece estarem de boa vontade.

Qual será então o papel da água neste aparelho?

Não será possivel dizer-se com certeza, pelo menos sem desmontar o aparelho. Mas o meu objectivo é dar uma contribuição para o processo educativo, e por isso defendo que devemos fazer raciocínios à base do que observamos sem destruir o aparelho, um objecto de 111 g cujo paralelepípedo envolvente teria cerca de $(10 \times 8 \times 5) \mathrm{cm}$ com 5 pequenos tubos para serem enchidos de água, levando ao todo ca. $40 \mathrm{~mL}$, isto é, pesando $151 \mathrm{~g}$ com a água.

Uma hipótese será admitir-se que a água é tão só um "interruptor" que fecha o circuito que liga uma pequena pilha ao mecanismo do relógio. Por outras palavras, a água é meramente um condutor de corrente eléctrica. E poderá ser desde que contenha sais dissolvidos, isto é, iões, o que é o caso da água da torneira ou de qualquer outra solução aquosa indicada no folheto.

Mas, claro, então o aparelho tem de ter uma pilha, e essa sim é que é a fonte de corrente. Naturalmente que o texto do folheto deveria ser revisto, pois diz "Nầo precisa de pilha para funcionar."

Para testar esta hipótese, substituí a água da torneira que enchia os tubos por água destilada: o relógio não funcionou! Dissolvi algum cloreto de sódio nessa mesma água destilada: o relógio logo começou a funcionar! Repeti o ensaio 2 vezes, sempre com os mesmos resultados. Mais, quando se coloca água destilada, havendo ainda resíduos de água da torneira, nota-se que os algarismos no visor aparecem mas de modo quase imperceptivel. Ora, a interpretação mais óbvia para estes ensaios é considerar que a solução colocada nos tubos serve só de condutor eléctrico: quando isenta de iōes não conduz a electricidade, logo, funciona como interruptor aberto; quando tem iões, conduz a corrente e funciona como fechando o circuito. Com poucos iōes a resistência é muito elevada e os algarismos mal se vêem.
Note-se que estes relógios digitais consomem muito pouca energia, pelo que uma pequena pilha de relógio, tal como temos nos nossos relógios digitais, dura muitos anos. Provavelmente a estrutura física do aparelho deteriora-se antes que a pilha se esgote, pelo que o utilizador ficaria convencido que o combustivel teria sido a água.

Outra hipótese seria admitir-se que a água iria funcionar de solução electrolítica (electrólito como por vezes se diz [3]) e a permitir reacções de oxidação e redução em dois eléctrodos previamente instalados. É a tal história das pernas de rãs que Galvani via contorcer-se quando penduradas por garras de cobre em fios de zinco, e que Volta depois estudou com cuidado, dai nascendo a corrente eléctrica, geradores electroquímicos ( $\mathrm{pi}$ Ihas e baterias), a tão útil electrodeposição de metais, enfim, a electroquímica como ciência.

Assim, bastaria que o tal relógio tivesse um pedacito de zinco (e.g. electrodepositado), outro de cobre coberto dos seus óxidos, e um espaço a ser ocupado pela água, ou melhor, pela solução electrolítica. Dar-se-iam as reacções

$\mathrm{Zn}(\mathrm{s}) \leftrightarrow \mathrm{Zn}^{2} \cdot(\mathrm{aq})+2 \mathrm{e}$

$\mathrm{Cu}^{2+}(\mathrm{aq})+2 \mathrm{e} \leftrightarrow \mathrm{Cu}(\mathrm{s})$

$\mathrm{Zn}(\mathrm{s})+\mathrm{Cu}^{2+}(\mathrm{aq}) \leftrightarrow \mathrm{Zn}^{2+}(\mathrm{aq})+\mathrm{Cu}(\mathrm{s})$

e teríamos uma pilha electroquímica [4] geradora de corrente eléctrica a alimentar o mecanismo do relógio. Mas a água não seria o combustivel! Seria sim mais um constituinte da pilha, e a energia advém daquela reacção, não da água.

As reacções (7), (8) e (9) traduzem a chamada pilha de Daniell, muito utilizada no séc. XIX para abastecer corrente eléctrica à vastíssima rede de telégrafos. É também a mais falada para fins de ensino.

Claro que há centenas de outras alternativas a este sistema de Daniell, que os construtores deste relógio a água poderiam utilizar.

Citei duas hipóteses quanto ao papel que a água (leia-se água com iões) po- 
deria representar no funcionamento do relógio: 1 - mero condutor de corrente ("interruptor"); 2 - electrólito de um sistema cujos eléctrodos fariam parte da construção do aparelho. Deixo para os leitores imaginarem outras hipóteses que, contudo, não poderão considerar a água como combustível. Elas poderão passar pelas mais sofisticadas técnicas de deposição de finos filmes dos constituintes químicos das actuais (ou futuras) pilhas para relógios, telemóveis, etc., só detectáveis por poderosas técnicas analíticas (raios X, microscopia electrónica de varrimento, etc.) até ... à fusão nuclear a frio! É com muito prazer que eu dou os meus parabéns aos construtores do aparelho: conseguiram criar algo que muito aguça o espírito dos interessados na ciência! É muito bom para motivar alunos para a compreensão de fundamentos científicos.
Não cabe aqui fazer comentários quanto ao uso dos vocábulos sobrevoltagem, transferência de carga, electrões extraídos das moléculas, etc. Talvez tenham sido usados por desconhecimento, pois não quero admitir que tenham sido atirados somente com o objectivo de impressionar o leitor, e não vejo no folheto qualquer justificação para o seu uso. Talvez aqui também seja de pedir aos professores que insistam muito com os seus alunos para nunca atirarem com palavras cujo significado não dominam bem.

Referências

[1] D-Mail Venda Directa SA, Parque Monserrate - Pavilhão C - Zona Industrial da Abrunheira, 27114-971, Tel. 219156 560,
E-mail assistência@dmail.pt. Foi dado como brinde na compra de outros produtos.

[2] Não pretendo entrar em significativas considerações termodinâmicas, nem mesmo falar de entalpia e entropia, pois dou conta que os alunos do secundário não os entendem, e gostaria que eles compreendessem o aqui exposto.

[3] V.M.M. Lobo (The definition of electrolyte) Port. Electrochim. Acta 14, 27 (1996);

V.M.M. Lobo (The definition of electrolyte: a comment from a reader and the author's

reply) Port. Electrochim. Acta 15, 215 (1997).

[4] V.M.M. Lobo (The use of basic concepts of electrochemistry in industry) Port. Electrochim. Acta 16, 221 (1998); V.M.M. Lobo (Necessidade de conhecimentos de electroquímica no âmbito da corrosão) Port. Electrochim. Acta 16, 165 (1998).

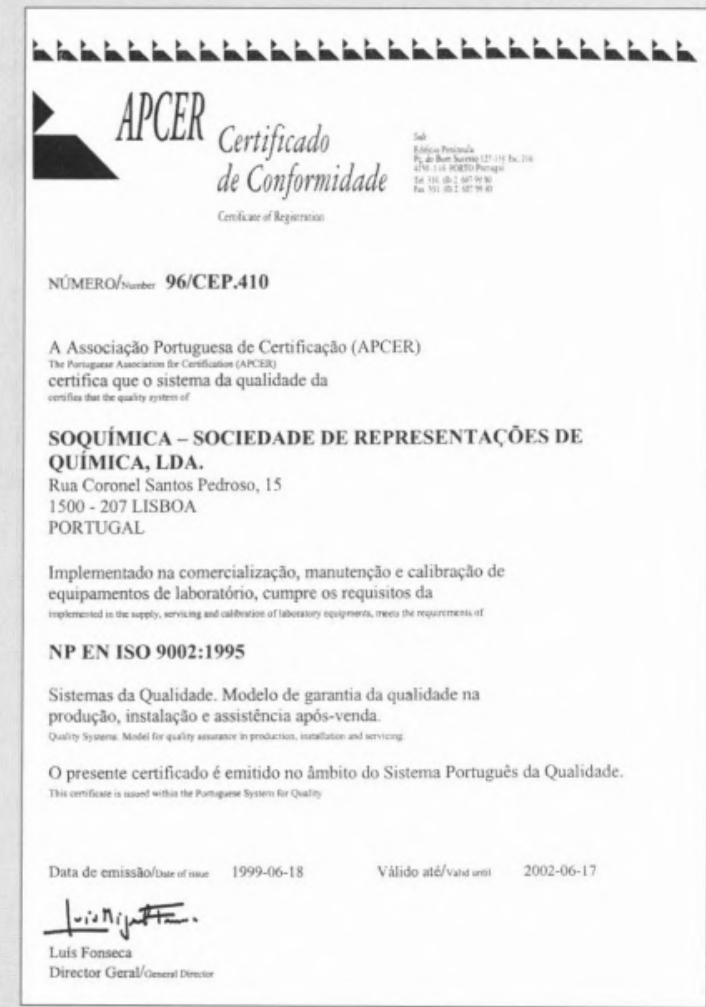

